\title{
Intracellular Biosynthesis and Antibacterial Activity of Silver Nanoparticles Using Edible Mushrooms
}

\author{
Sankaran MIRUNALINI*,Vadivel ARULMOZHI, Krishnamoorthy \\ DEEPALAKSHMI, Mani KRISHNAVENI
}

Annamalai University, Faculty of Science, Department of Biochemistry and Biotechnology, Annamalainagar,

Tamil Nadu, India; mirunasankar@gmail.com (*correspondent author)

\begin{abstract}
The process of biosynthesis of silver nanoparticles is a simple, cost effective and eco-friendly approach. Biosynthesis of silver nanoparticles using some commonly available edible mushroom extracts and their antimicrobial activity was demonstrated in the current study. The formation of silver nanoparticles was confirmed by UV, FTIR and SEM and antibacterial activity was tested using disc diffusion method. From the results it is confirmed the successful formation of silver nanoparticles using mushroom extracts; they performed their role as a reducing and capping agent and also exhibited a potent antibacterial activity against $S$. aureus (gram positive bacteria). Thus the biosynthesis of silver nanoparticles using edible mushroom extract will deserve to be a good candidate as an antibacterial agent.
\end{abstract}

Keywords: antibacterial activity, biosynthesis, edible mushrooms, silver nanoparticles

\section{Introduction}

Despite the fact of advances in developing new drugs against various infectious diseases, till date there is a growing concern about the emergence and re-emergence of drug resistance. Currently nanotechnology has paved way in developing novel drugs mainly in the field of medicine. The use of nanoparticles is presently gaining impetus as they posses defined chemical, optical and mechanical properties. They are most promising as they show good antibacterial properties due to their large surface area to volume ratio, which is coming up as the current interest in the researchers, due to the growing microbial resistance against metal ions, antibiotics and the development of resistant strains (Gong et al., 2007). Different types of nanomaterials like copper, zinc, titanium (Retchkiman-Schares et al., 2006), magnesium, gold (Gu et al., 2003), alginate (Ahmad et al., 2005) and silver have recently come up for the synthesis of silver nanoparticles. Among other noble metals, silver nanoparticles have proved to be most effective as it has good antimicrobial efficacy against bacteria, viruses and other eukaryotic micro-organisms. Since ancient times silver has been used for burn wounds treatment, dental work, catheters and bacterial infection control, in forms of metallic silver, silver nitrate, and silver sulfadiazine Previously, nanoparticles were synthesized only by physical and chemical methods. Nowadays researchers are showing much interest on biological mediated synthesis using plants, fungi, microbes and yeast (Philip, 2009; Tripathy et al., 2009). Extracts from bio-organisms may act both as reducing and capping agents in Ag NPs synthesis. The reduction of $\mathrm{Ag}+$ ions by combinations of biomolecules found in these extracts, such as enzymes/proteins, amino acids, polysaccharides, and vitamins, is environmentally benign, yet chemically complex. This was achieved either through intracellular and extracellular synthesis (Acosta, 2009).

Mushrooms have been part of the normal human diet for thousands of years and in recent times, the amounts consumed have risen greatly, involving a large number of species. Generally edible mushrooms are used for nutritional and therapeutic purposes (Borchers et al., 2004; Chang, 1996; Ribeiro and Salvadori, 2003). Apart from this, they are valuable health foods since they are low in calories, fats, essential fatty acids and high in vegetable proteins, vitamins and minerals (Murugkar and Subbulakshmi, 2005). Among various mushrooms Calocybe indica (milky mushroom) [CI], Pleurotus ostreatus (oyster mushroom) [PO], Agaricus bisporous (button mushroom) [AB] and Ganoderma lucidum (reishi mushroom) [GL] which are commonly available edible mushrooms, revealed to possess wide beneficial properties such as antioxidant, anticancer, antimicrobial (Lillian et al., 2008). Due to its increased nutritive and therapeutic values herein we focussed on the simple and ecofriendly approach to synthesis silver nanoparticles using the above mentioned edible mushrooms and further evaluated its antibacterial activity. 
56

\section{Materials and methods}

Chemicals

All chemicals were of analytical grade and procured from Sigma Aldrich (India) or Merck (India) unless otherwise stated. The culture media were purchased from $\mathrm{Hi}$ Media (India).

\section{Preparation of intracellular mushroom extract}

$20 \mathrm{~g}$ of fruiting bodies of edible mushrooms ( $\mathrm{PO}, \mathrm{AB}$, GL and CI) were taken separately and rinsed thrice in distilled water, dried on a tissue paper and cut in fine pieces until they were made into a paste, and finally boiled in $100 \mathrm{ml}$ of sterile distilled water up to 5 minutes. It was filtered using whatman No: 41 filter paper and stored at $4^{\circ} \mathrm{C}$.

\section{Intracellular Biosynthesis of Silver Nanoparticles}

$1 \mathrm{mM}$ aqueous solution of silver nitrate (AgNO3) was prepared and used for the synthesis of silver nanoparticles. $10 \mathrm{ml}$ of mushroom extract was added into $90 \mathrm{ml}$ of aqueous solution of $1 \mathrm{mM}$ silver nitrate for reduction into $\mathrm{Ag}+$ ions and incubated overnight at room temperature in dark.

\section{UV-Vis Spectral Analysis of Silver Nanoparticles}

The reduction of pure Ag+ ions was monitored by measuring the UV-vis spectrum of the reaction medium after overnight incubation, after diluting a small aliquot of the sample into distilled water. Silver nanoparticles (AgNPs) are soluble in distilled water and the colour changes were observed visually. A yellowish brown colouration was noticed at the synthesis phase. The concentration of AgNP produced was measured using a Systronics UV double-beam spectrophotometer (model 2201), at a resolution of $1 \mathrm{~nm}$, between 200 and $600 \mathrm{~nm}$, using $10-\mathrm{mm}$ -optical- path- length quartz cuvettes.

\section{Fourier Transform Infrared Spectroscopy (FTIR)}

FT-IR spectra were measured using Nicolet-Avatar 300 FT-IR spectrometer. About $5 \mathrm{mg}$ of sample were mixed with $100 \mathrm{mg}$ of $\mathrm{KBr}$ and compressed into pellet using a hydraulic press. FT-IR spectra over the scanning range of $4000-400 \mathrm{~cm}^{-1}$ were obtained with the resolution of 2 $\mathrm{cm}^{-1}$.

Preparation of Silver Nanoparticles Sample for SEM Studies

The morphological features of synthesized nanoparticles were examined by scanning electron microscopy (JEOL 6380A, Japan).

\section{Antibacterial activity of Silver nanoparticles}

Antibacterial activity of medicinal compounds is treated through Disc diffusion methods, most commonly employed method to evaluate the antibacterial activity. In the present study we have used the disc diffusion method to check the antibacterial activity of mushroom extracts. The disc diffusion techniques are widely used in Kirby-Bauer method.

Disc diffusion was carried out for the bacterial suspension containing $10^{6}$ cells. Plates with Nutrient agar were seeded and then drained off. They were desiccated at room temperatute for 15-20 min for adequate drying. The disc prepared from fruiting bodies extract was placed in quadrangular manner in different petri dishes. Then petri dishes were incubated at $30 \pm 2^{\circ} \mathrm{C}$ for 24 hours. After $24-48$ hours results were noted for the zone of inhibition, which was measured in $\mathrm{mm}$.

\section{Results and discussion}

The current study focused on some edible mushrooms which mediated the synthesis of silver nanoparticles and also investigated for its antimicrobial activity. Even though several approaches have been reported to synthesize AgNPs, currently biological mediated synthesis has received great interest in the scientific community. Since mushrooms are highly enriched with proteins it is suspected that they act as reducing, as well as capping, agent.

\section{Biosynthesis of silver nanoparticles}

Synthesis of silver nanoparticles using PO, AB, GL and CI extract was observed (Fig. 1). When mushroom extract was individually subjected to aqueous solution of silver nitrate, a gradual change of colour was observed after 48 hrs. PO, AB and GL extract changed its colour to reddish brown, while CI extract changed its colour to yellow, indicating the formation of silver nanoparticles after $48 \mathrm{hrs}$. This change of colour could be due to the formation of silver nanoparticles of varying shape and size. Our result coincides with the recent report of Philip (2009). The formation of reduced AgNPs reaction mixture was further characterised by UV-vis spectrophotometry.

Generally, silver nanoparticles absorb in the visible region of the electromagnetic spectrum at $380-450 \mathrm{~nm}$, due to the surface plasmon resonance (SPR) transition. In the present study the reduction of silver ions to silver nanoparticles using $\mathrm{PO}, \mathrm{AB}$ and $\mathrm{GL}$ mushroom extracts was completed within $48 \mathrm{hrs}$ whereas the reduction of the reaction mixture for CI extract was completed within $24 \mathrm{hrs}$ and there was no further reduction. The nanoparticles synthesized using $\mathrm{PO}$ extract were absorbed at $420 \mathrm{~nm}$, with $\mathrm{AB}$ extract at $410 \mathrm{~nm}$, with GL extract it was absorbed at 430 $\mathrm{nm}$ and CI extract was absorbed at $400 \mathrm{~nm}$. Thus all the nanoparticles synthsized using mushroom extract showed the absorption spectra between $400-430 \mathrm{~nm}$, which indicates the presence of silver nanoparticles, which is due to the excitation of surface plasmon resonance in the metal nanoparticles (Mulvaney, 1996). After 48 hrs of incubation, no further increase of the intensity was recorded, indicating complete reduction of precursor silver ions. This formation of AgNPs was mediated by the active biomol- 

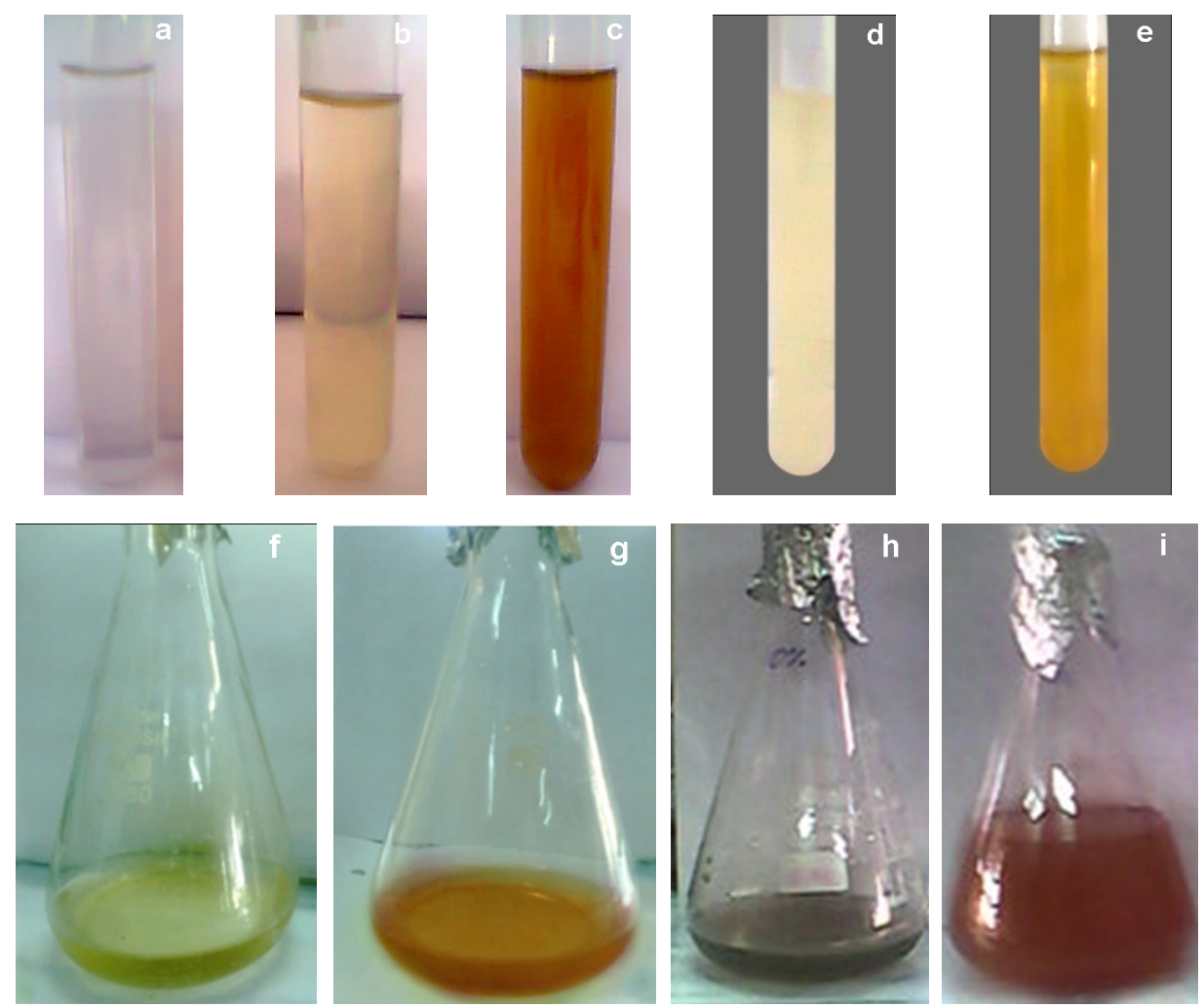

Fig. 1. Optical photograph of a) $\mathrm{AgNO}_{3}$, b) $\mathrm{PO}$, c) $\mathrm{PO}+\mathrm{AgNo}_{3}$, d) $\mathrm{AB}$, e) $\left.\mathrm{AB}+\mathrm{AgNo}_{3}, \mathrm{f}\right) \mathrm{GL}$,

g) $\left.\left.\mathrm{GL}+\mathrm{AgNo}_{3}, \mathrm{~h}\right) \mathrm{CI}, \mathrm{i}\right) \mathrm{CI}+\mathrm{AgNo}_{3}$ before and after $48 \mathrm{hrs}$ of reaction

ecules present in the mushroom extracts. Strictly pursuing Philips et al. (2011), has also reported the biosynthesis of AgNPs using edible mushroom which strongly supports our result.

\section{FTIR analysis of $P O$ and PO-AgNPs}

FTIR measurements showed the evidence of possible interactions between silver and bioactive molecules of mushroom extract, which may be responsible for the synthesis and stabilization (capping material) of silver nanoparticles. Fig. 2 shows the FTIR spectra of $i$ ) PO extract and PO-AgNPs, ii) $\mathrm{AB}$ extract and AB-AgNPs, iii) GL extract and GL-AgNPs, iv) CI and CI-AgNPs. The FTIR peaks determined the bonds relevant to amine $\mathrm{N}-\mathrm{H}$ stretching, aldehyde $\mathrm{C}-\mathrm{H}$ stretching, bending vibration of amide I and II, carboxylic acid stretching and aromatic ring stretching. Silver nanoparticles usually absorb strongly at $1679,1539,1452,1430$ and $1040 \mathrm{~cm}^{-1}$ (Justin Packia Jacob et al., 2012).

In this study PO-AgNPs showed intense absorption at $1649,1544,1459,1397,1082 \mathrm{~cm}^{-1}$ which is assigned to be amide I and II group and C-N stretching vibrations of aromatic ring; this strongly proves the association of $\mathrm{PO}$ in reducing silver ions. In the spectra of $\mathrm{AB}$ and $\mathrm{AB}-\mathrm{AgNPs}$ exhibited vibration at $1635 \mathrm{~cm}^{-1}$ and $1545 \mathrm{~cm}^{-1}$ found in $\mathrm{AB}-\mathrm{AgNPs}$ are the bending vibrations of the amide $\mathrm{I}$ and II, which clearly indicates the presence of proteins in the $A$. bisporous mushroom extract. The bands observed at 1320 ,
1243 and $1047 \mathrm{~cm}^{-1}$ can be assigned to the C-N stretching vibrations of aromatic and aliphatic amines respectively. GL extract showed the absorption peak at $3433 \mathrm{~cm}^{-1}$. which is assigned to $\mathrm{O}-\mathrm{H}$ stretching of alcoholic groups. The peak at $1742 \mathrm{~cm}^{-1} \mathrm{can}$ be assigned an absorption peaks of $\mathrm{C}=\mathrm{O}$, while the peak at $1629 \mathrm{~cm}^{-1}$ corresponds to $\mathrm{N}-\mathrm{H}$ bending vibrations of the amide I and II, which clearly indicates the presence of proteins in the G. lucidum extract. The absorbance peak at 1358, 1326, 1210 and $1054 \mathrm{~cm}^{-1}$ corresponds to C-N stretching respectively. CI extract exhibited vibration at $3418 \mathrm{~cm}^{-1}$ and $3422 \mathrm{~cm}^{-1}$, which is assigned to the $\mathrm{N}-\mathrm{H}$ group from peptide linkage present in the extract. $1641 \mathrm{~cm}^{-1}$ and $1550 \mathrm{~cm}^{-1}$ absorbed in CIAgNPs are the bending vibrations of the amide I and II, which clearly indicates the presence of proteins in the $C$. indica mushroom extract. CI-AgNPs showed intense absorption at $1641,1550,1458,1387,10782 \mathrm{~cm}^{-1}$, which strongly proves the association of $C$. indica in reducing silver ions.

These variations of $\mathrm{N}-\mathrm{H}, \mathrm{O}-\mathrm{H}$ and other infrared bands, suggests the formation of silver nanoparticles using $\mathrm{PO}, \mathrm{AB}, \mathrm{GL}$ and $\mathrm{CI}$ extract. It is well known that these edible mushrooms posses various phytochemicals like proteins, polysaccharides and amino acids which have acted as a bioreductant for the biosynthesis of silver nanoparticles. It is also possible that proteins/enzymes play a role in the reduction of metal ions by the oxidation of benzaldehyde 

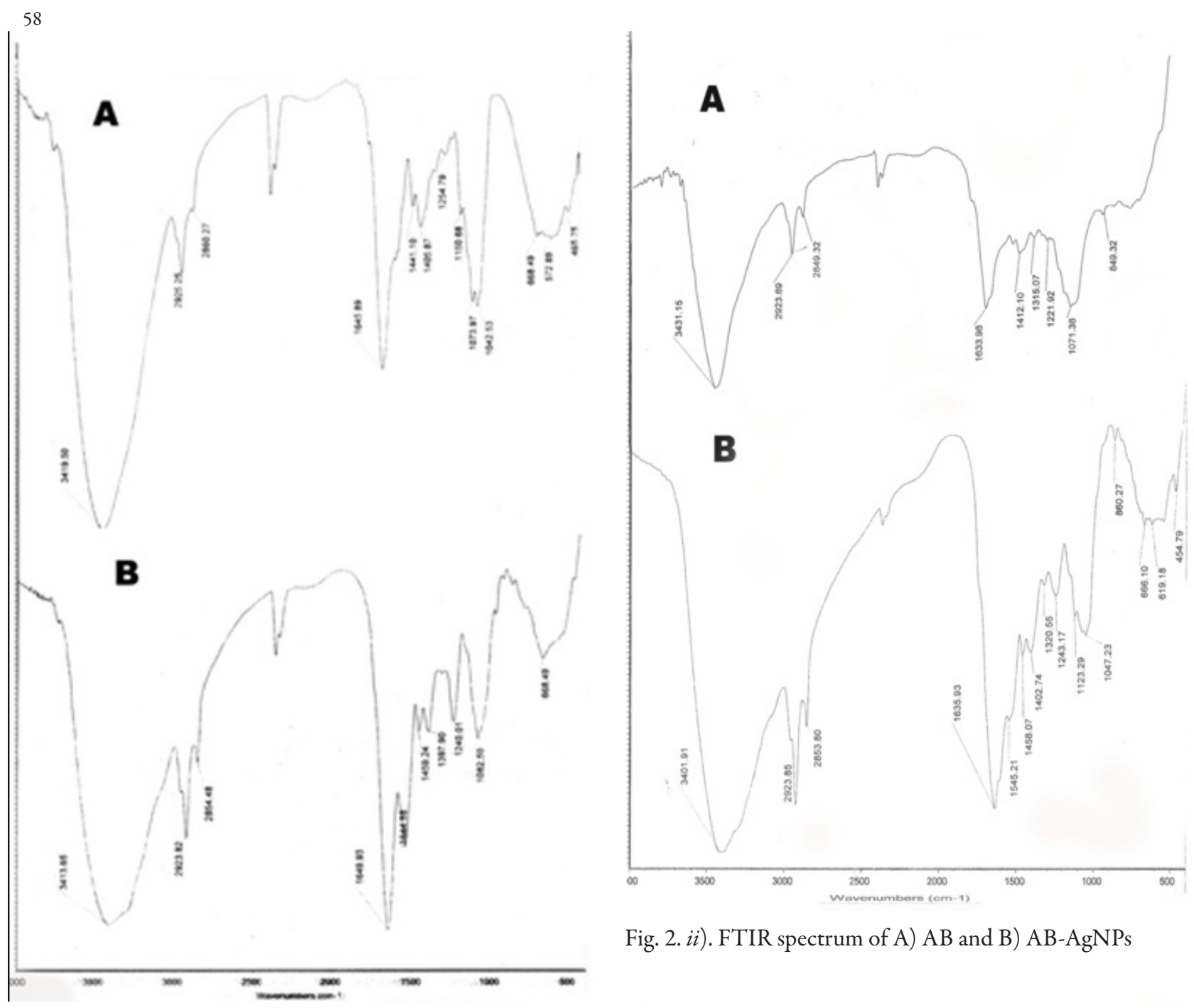

Fig. 2. ii). FTIR spectrum of $A) A B$ and $B) A B-A g N P s$

Fig. 2. i). FTIR spectrum of A) PO and B) PO-AgNPs
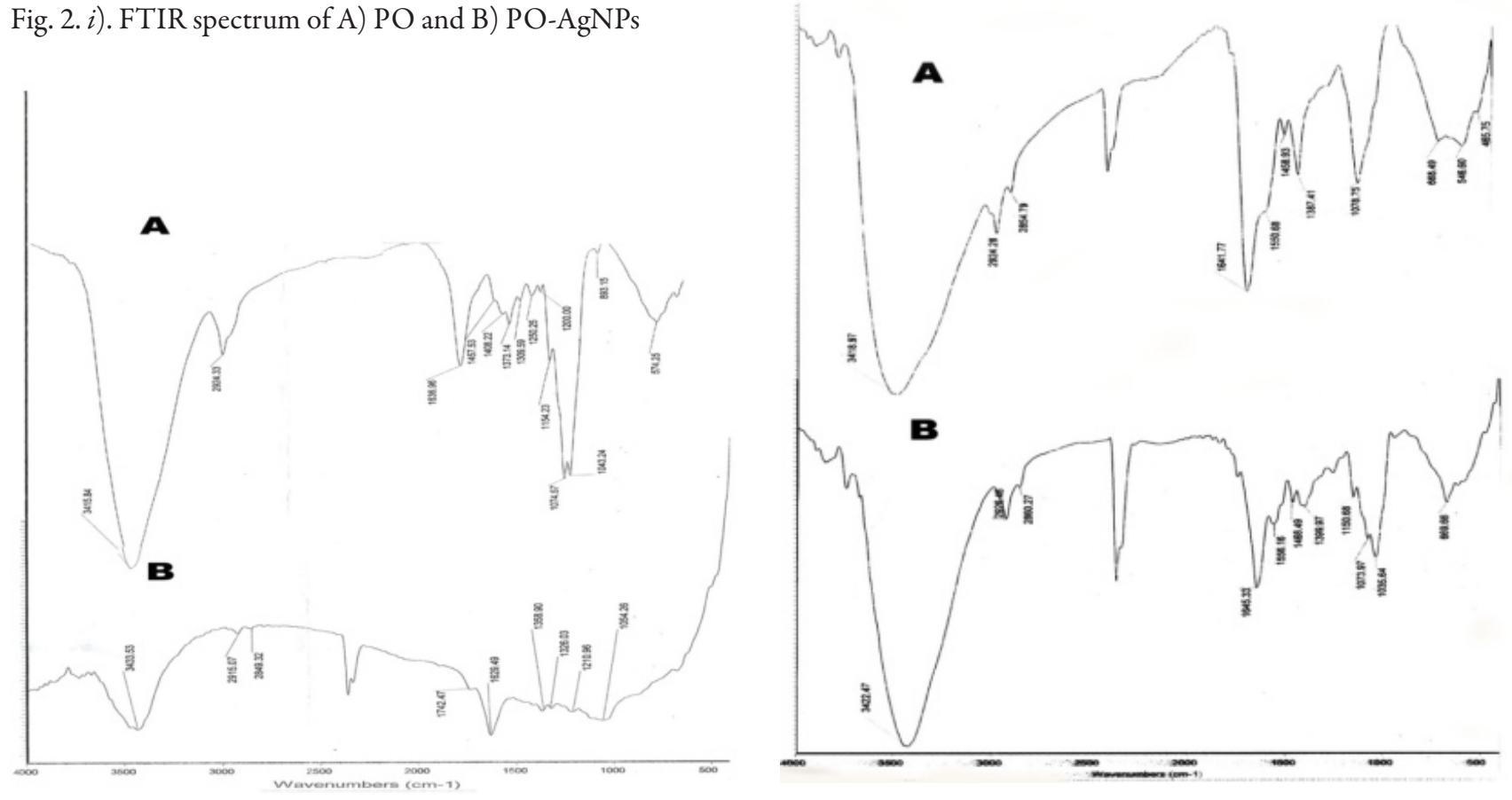

Fig. 2. iii). FTIR spectrum of A) GL and B) GL-AgNPs 

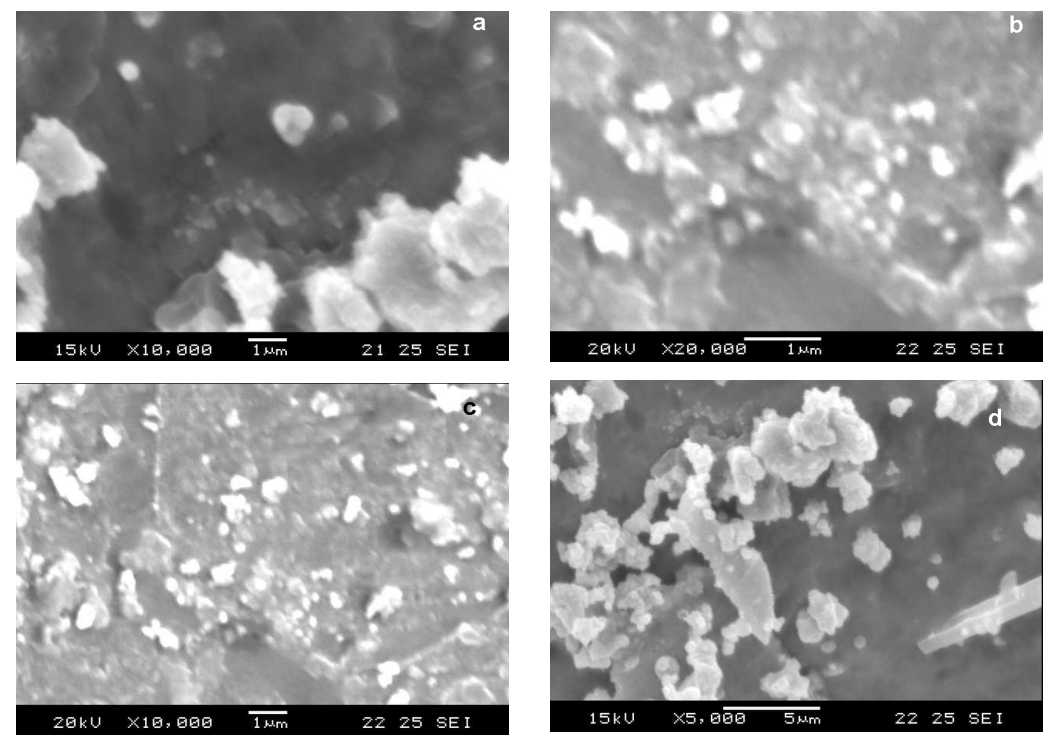

Fig. 3. SEM images of a) PO-AgNPs, b) AB-AgNPs, c) GL-AgNPs, d) CI-AgNPs

(aldehyde groups) to carboxylic acids (Mandal et al., 2006; Philip, 2009; Shankar et al., 2004).

\section{SEM analysis}

The morphology and the particle size of Ag NPs synthesized using $\mathrm{PO}, \mathrm{AB}, \mathrm{GL}$ and $\mathrm{CI}$ extract was determined using SEM micrograph (Fig. 3). NPs synthesized using PO seems to be spherical with agglomerated particles and the sizes found are roughly in the range of $100 \mathrm{~nm}$. SEM micrograph of AB-Ag NPs showed to be spherical in aggregated form and its size range was of $80-100 \mathrm{~nm}$. GL-Ag NPs was spherical in shape, with its size around $50 \mathrm{~nm}$. CI-Ag NPs was also found to be spherical in shape, with its size range around $100 \mathrm{~nm}$, thus proving it to be a nanoparticle.

\section{Antibacterial activity}

Bacterial clinical isolates normally exhibit higher levels of resistance to antibiotics, as they are under continuous selective antibiotic stress in medical care facilities (Rahman et al., 2012). Moreover, bacterial strains associated with food-related outbreaks may also demonstrate higher levels of resistance, likely due to the use of antibiotics in animal husbandry (Smith et al., 2002). It is widely proved that silver nanoparticles have showed good antibacterial activity against different bacterial strains (Bankura et al., 2012). Numerous reports have stated the antibacterial activity of Ag NPs (Hindi et al., 2009; Lansdown, 2002; Morones et al., 2005). In the present study the antibacterial activity of silver nanoparticles was investigated against pathogenic bacteria of gram positive strains using disc diffusion method. The antibacterial activity of synth-
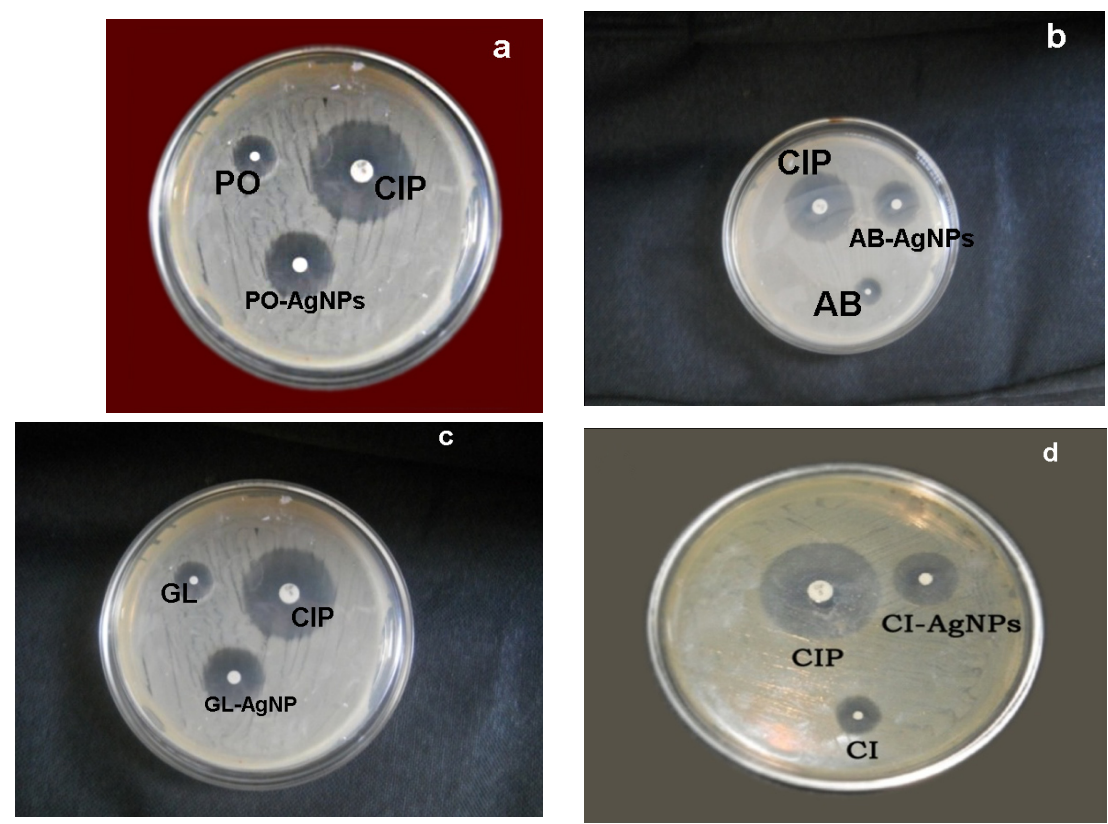

Fig. 4. Antimicrobial activity of silver nanoparticles against $S$. aureus (gram positive) 
60

sized PO-AgNPs, AB-AgNPs, GL-AgNPs and CI-AgNPs against gram positive (Staphylococcus aureus) bacteria was evaluated using standard zone of inhibition (Fig. 4 and Tab. 1). Ciproflaxacin was used as a reference antimicrobial drug. The diameter of inhibitory zones on both free extract and AgNPs were represented in Tab. 1. PO and GL AgNPs showed maximum zone of inhibition at $7 \mathrm{~mm}$ and $8 \mathrm{~mm}$, where as for $\mathrm{AB}$ and $\mathrm{CI} A \mathrm{AgNP}$ s the inhibitory zone was around $6 \mathrm{~mm}$. In the case of mushroom extract the inhibitory zone was less when compared to their respective AgNPs, which proved to have less antimicrobial activity. From our results we suggest that AgNPs exhibited antibacterial activity against gram positive bacteria while the exact mechanism of the antibacterial effect of silver ions is not exactly known. The antibacterial activity is probably derived through the electrostatic attraction between negative charged cell membrane of microorganism and positive charged nanoparticles (Dibrov et al., 2002). Shrivastava et al. (2007), studied antibacterial activity against $E$. coli and $S$. aureus. This potential antimicrobial activity of silver nanoparticles has made them promising candidates as an antimicrobial agent.

\section{Conclusion}

Synthesis of silver nanoparticles using various edible mushrooms extracts was developed in a very simple and eco-friendly method. Generally, mushrooms containing proteins have played a major role in acting as a reductant as well as a capping material in order to synthesize a novel AgNPS and functioned more effectively as an antimicrobial agent against gram positive bacterial strains. Thus, the prospect of rational use of mushrooms in synthesizing metallic nanoparticles is an exciting and very simple biological method which will prompt with high outlook in future, especially in various medicinal fields.

\section{References}

Acosta E (2009). Bioavailability of nanoparticles in nutrient and nutraceutical delivery. Curr Opin Coll Int Sci 14:3-15.

Ahmad Z, Pandey R, Sharma S, Khuller GK (2005). Alginate nanoparticles as antituberculosis drug carriers: formulation development, pharmacokinetics and therapeutic potential. Ind J Chest Dis Allied Sci 48:171-176.

Bankura KP, Maity D, Mollick MMR, Mondal D, Bhowmick B, Bain MK, Chakraborty A, Sarkar J, Acharya K, Chattopadhyay D (2012). Synthesis, Characterization and Antimicrobial Activity of Dextran Stabilized Silver Nanoparticles in Aqueous Medium. Carbohydrate Polymers 89:1159-1165.

Borchers AT, Keen CL, Gershwin ME (2004). Mushrooms, tumors, and immunity: an update. Exp Biol Med (Maywood) 229:393-406.

Chang R (1996). Functional properties of edible mushrooms. Nutr Rev 54(11 Pt 2):S91-S93.
Dibrov P, Dzioba J, Gosink KK, Hase CC (2002). Chemiosmotic Mechanism of Antimicrobial Activity of $\mathrm{Ag}^{+}$in $\mathrm{Vi}$ brio cholera. Antimicrob Agents Chemother 46:2668-2670.

Gong P, Li H, He X, Wang K, Hu J, Tan W (2007). Preparation and antibacterial activity of $\mathrm{Fe}_{3} \mathrm{O}_{4} \mathrm{Ag}$ nanoparticles. J Nanotechnol 18:604-611.

Gu H, Ho PL, Tong E,Wang L, Xu B (2003). Presenting vancomycin on nanoparticles to enhance antimicrobial activities. Nano Lett 3(9):1261-1263.

Hindi KM, Ditto AJ, Panzner MJ, Medvetz DA, Han DS, Hovis CE, Hilliard JK, Taylor JB, Yun YH, Cannon CL, Youngs WJ (2009). The antimicrobial efficacy of sustained release silver-carbene complex-loaded l-tyrosine polyphosphate nanoparticles: characterization, in vitro and in vivo studies. Biomaterials 30:3771-3779.

Justin Packia Jacob S, Finub JS, Anand Narayanan (2012). Synthesis of silver nanoparticles using piper longum leaf extracts and its cytotoxic activity against Hep-2 cellline. J Colloid and surfaces B: Biointerfaces 91:212-214.

Lansdown AB (2002). Silver. 1: Its antibacterial properties and mechanism of action. J Wound Care 11:173-177.

Lillian B, Telma C, Paula B, Leticia ME, Isabel CF, Ferreira R (2008). Wild and commercial mushrooms as source of nutrients and nutraceuticals. Food Chem Toxicol 46:2742-2747.

Mandal D, Bolander ME, Mukhopadhay D, Sarkar G, Mukherjee $P$ (2006). The use of microorganisms for the formation of metal nanoparticles and their application. Appl Microbiol Biotechnol 69:485.

Morones JR, Elechiguerra JL, Camacho A, Holt K, Kouri JB, Ramirez JT (2005). The bactericidal effect of silver nanoparticles. J Nanotechnol 16:2346-2353.

Mulvaney P (1996). Surface plasma spectroscopy of nanosized metal particles. Langmuir 12:788.

Murugkar AD, Subbulakshmi G (2005). Nutritional value of edible wild mushrooms collected from the Khasi hills of Meghalaya. Food Chem 89:599-603.

Philip D, Unni C, Aromal SA, Vidhu VK (2011). Murraya koenigii leaf-assisted rapid green synthesis of silver and goldnanoparticles. Spectrochim Acta Part A 78: 899-904.

Philip D (2009). Biosynthesis of Au, Ag and Au-Ag nanoparticles using edible mushroom extract. Spectrochim Acta Part A 73:374-381.

Rahman MM, Richardson A and Sofian-Azirun M (2012). Antibacterial activity of propolis and honey against Staphylococcus aureus and Escherichia coli. Afr J Microbiol Res 4:1872-1878.

Retchkiman-Schabes PS, Canizal G, Becerra-Herrera R, Zorrilla C, Liu HB, Ascencio JA (2006). Biosynthesis and characterization of $\mathrm{Ti} / \mathrm{Ni}$ bimetallic nanoparticles. Opt Mater 29:95-99.

Ribeiro LR, Salvadori DM (2003). Dietary components may prevent mutation-related diseases in humans. Mutat Res 544:195-201. 
Shankar S, Rai A, Ahmad A, Sastry M (2004). Rapid synthesis of Au, Ag and bimetallic Au core-Ag shell nanoparticles using neem (Azadirachta Indica) leaf broth. J Colloid Interf Sci 275:496.

Shrivastava S, Bera T, Roy A, Singh G, Ramachandrarao P, Dash D (2007). Applying Nanotechnology to Human Health: Revolution in Biomedical Sciences. J Nanotechnol 18:225103-225111.

Smith DL, Harris AD, Johnson JA, Silbergeld EK, Morris Jr JG
(2002). Animal antibiotic use has an early but important impact on the emergence of antibiotic resistance in human commensal bacteria. Proc Nat Acad Sci 99:5752-5754.

Tripathy A, Chandrasekaran N, Raichur AM, Mukherjee A (2009). Process variables in biomimetic synthesis of silver nanoparticles by aqueous extract of Azadirachta indica (Neem) leaves. J Biomed Nanotechnol 5:93-98. 